\title{
New Genus, a New Species, and Complements to the Descriptions of Seven Neotropical Dicranocentrus (Collembola: Entomobryidae: Orchesellinae) $)^{1,2}$
}

\begin{abstract}
José A. Mari Mutt ${ }^{3}$
ABSTRACT

A new genus, Pseudodicranocentrus, is erected for two species (circulatus and christianseni) previously described and placed by the author in the genus Dicranocentrus. The new genus is similar to the latter but differs by the presence of head setae $A_{1}$, Ps, bifurcated prelabral setae, and circularly arranged compound spines on the dental lobe. D. biseriatus $\mathrm{n}$. $\mathrm{sp}$. from Haiti and $D$. antillensis jamaicensis $n$. ssp. from Jamaica are described. D. millsi cubensis Mari Mutt 1979 is synonymized to the nominal form. Details are added to the descriptions of the following neotropical Dicranocentrus: antillensis, colombiensis, marias, millsi, nigritus, platensis and schoetti.
\end{abstract}

\section{INTRODUCTION}

Soon after my revision of Dicranocentrus (9) went to the printers, I undertook a similar study with the scaled Orchesellinae (6). Since the head and body macrochaetotaxy of Dicranocentrus species provide excellent diagnostic characters and suffice for the identification of most species, characters beside those already used in the genus were not sought.

Such is not the case with the holarctic species of Heteromurus s. str. The seven members of this taxon share identical patterns of head macrochaetotaxy and all except $H$. peyerimhoffi Denis also share the same body macrochaetotaxy. Furthermore, the pattern of Denis' species differs from those of the others only with respect to the second thoracic segment (Th. 2). It was hence necessary to search for new characters and to apply some of those that were being used with success in other groups: morphology of labral papillae, chaetotaxy of the labial triangle, shape of maxillary palp setae, relative lengths of the outer labial papilla and its differentiated seta, type of setae (smooth or ciliated) along the ventral

${ }^{1}$ Manuscript submitted to Editorial Board December 17, 1979.

${ }^{2}$ This contribution is partly based on a thesis deposited by the author in the Graduate College of the University of Illinois at Urbana-Champaign, in partial fulfillment of the requirements for the degree of Doctor of Philosophy, Entomology, 1978.

${ }^{3}$ Department of Biology, University of Puerto Rico, Mayagüez, Puerto Rico 00708. The author is grateful to the staff of the Faunistics Section of the Illinois Natural History Survey, Urbana, Illinois, for their encouragement and support during his four-year stay there. His appreciation also goes to Dr. Judith Najt, Laboratoire de Zoologie, Université Paul Sabatier, Toulouse, France, for her gift of the specimens used in the redescription of Dicranocentrus platensis (Izarra). 
cephalic groove immediately behind the labial triangle (the four anterior setae form the post-labial quadrangle or PLQ), and the presence or absence of smooth setae on the dorsum of the manubrium.

I also took the opportunity to reexamine the material of Dicranocentrus still at hand and to rote the expression of these characters. Most frequently the new discoveries reinforced the conclusions derived from macrochaetotaxy but more important results were obtained. I have now realized that the circulatus group of species should be regarded as a new genus, Pseudodicranocentrus. It was also possible to locate $D$. biseriatus n. sp. among the type material of D. millsi Mari Mutt 1979 and to recognize a new subspecies of $D$. antillensis Mari Mutt 1979. The previous Mari Mutt (9) descriptions of seven other neotropical Dicranocentrus are expanded.

\section{RESULTS}

\section{GENUS PSEUDODICRANOCENTRUS NEW GENUS}

General appearance Orcheselline (fig. 3, Mari Mutt (9): 29, fig. 17). Length of adults, excluding antennae and furcula, 2.6-4.0 mm. Pigment blue-violet. Color pattern slightly variable intraspecifically. Head, body, first four antennal segments (Ants. 1-4), legs, and venter of furcula with striated brown scales that are apically rounded or truncated when fully developed.

Antennae 6-segmented. Ants. 5\&6 annulated, subequal in length. Antennae $1 / 2$ to $3 / 4$ length of head and body combined. Ant. 6 apically with pin seta in $P$. circulatus, seta not seen in christianseni but only one antenna examined. Head macrochaetotaxy polychaetotic (see Mari Mutt (9): 41, fig. 55; 42 figs. 63,64), $\mathrm{A}_{1}$ and Ps present. Eyes 8\&8, eyes g\&h not markedly reduced in diameter (fig. 5). Prelabral setae subequal in length, apically bifurcated (fig. 1). Labral chaetotaxy 5,5,4; all setae smooth. Labral papillae of type I (fig. 9). Seta E of second labial row smooth or ciliated; all setae of posterior row ciliated, number of setae variable. Setae of maxillary palp similar in shape but subapical seta longer (fig. 7). Differentiated seta of outer labial papilla slender, placed far back on its papilla, not reaching apex of latter (fig. 4). Setae of PLQ ciliated, other setae of venter of head also cilated.

Tibiotarsi with or without smooth setae depending on species. Unguis with inner basal pair of teeth and with 1 or 2 (depending on species) distal unpaired teeth. Unguiculus with outer tooth. Pretarsal setae present. Tenent hair apically lanceolate (christianseni) or clavate (circulatus). Body macrochaetotaxy polychaetotic (see Mari Mutt (9): 46, fig. 88; 47, fig. 90). Manubrium and dorsal proximal portion of dentes without smooth setae. Manubrial organ absent. Dental lobe with 3 groups of 

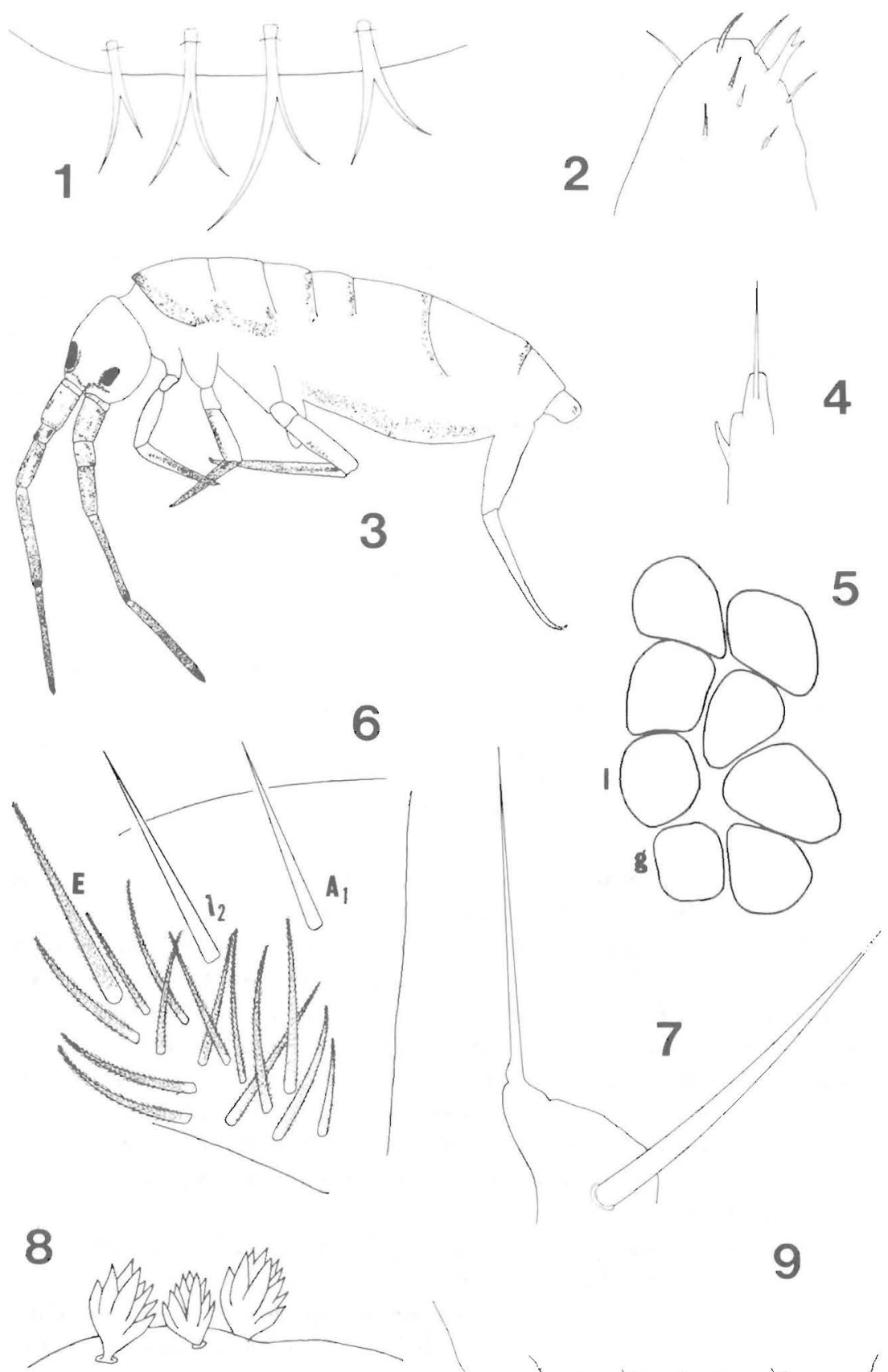

9

Plate I. Pseudodicranocentrus circulatus.

1. Bifurcated prelabral setae. 2. Apex of Ant. 6 with pin seta. 3. Habitus and distribution of pigment. 4. Outer labial papilla with its differentiated seta. 5. Right eye patch, note the size of eyes g\&h (compare with figure 55). 6. Labial triangle, note ciliated E seta. 8. Circularly arranged compound spines on dental lobe. 9. Labral papillae (type I). 
circularly arranged compound spines (fig. 8); spines absent from rest of dens. Mucro normal, with 2 teeth and basal spine.

Type Species

Dicranocentrus circulatus Mari Mutt 1979.

\section{Diagnosis}

The genus is closer to Dicranocentrus Schött 1893 (11) but differs from it by the presence of seta $A_{1}$ and $P_{s}$ on the head, bifurcated prelabral setae, and circularly arranged compound spines on the dental lobe.

Geographic distribution

Southern Mexico (Oaxaca, Puebla) and Guatemala (Yepocapa).

\section{Key to Species}

Note: Numbers followed by an asterisk (*) refer to figures in Mari Mutt (9).

Body macrochaetotaxy as in figure $89^{*}$; tibiotarsi with inner rows of smooth setae; pigmentation as in figure 17*; ungues tridentate (fig. $\left.42^{*}\right)$ christianseni Body macrochaetotaxy as in figure $90^{*}$; tibiotarsi without smooth setae; pigmentation as in figure 3 ; ungues quadridentate (fig. $\left.39^{*}\right)$ circulatus

\section{Descriptions $^{4}$}

Pseudodicranocentrus circulatus (Mari Mutt) NEW COMBINATION Dicranocentrus circulatus Mari Mutt 1979 (9): 21.

Habitus and pigmentation as in figure 3. Pin seta as in figure 2. Eyes g\&h not markedly reduced in diameter (fig. 5). Prelabral setae apically bifurcated (fig. 1). Labral papillae (fig. 9) of type I (all papillae with spinelike process). Labial chaetotaxy as in figure 6; seta $\mathrm{E}$ and setae of posterior row ciliated. Setae of maxillary palp as in figure 7. Differentiated seta of outer labial papilla as in figure 4. Setae of PLQ and all other setae of venter of head ciliated. Furcula without smooth setae.

Pseudodicranocentrus christianseni (Mari Mutt) NEW COMBINATION

Dicranocentrus christianseni Mari Mutt 1979 (9): 21.

Pin seta of Ant. 6 not found but only one antenna examined. Labial

${ }^{4}$ Unless otherwise stated, material examined is that kept in the Illinois Natural History Survey and listed in my 1979 revision of the genus. These descriptions complement those in said revision. 


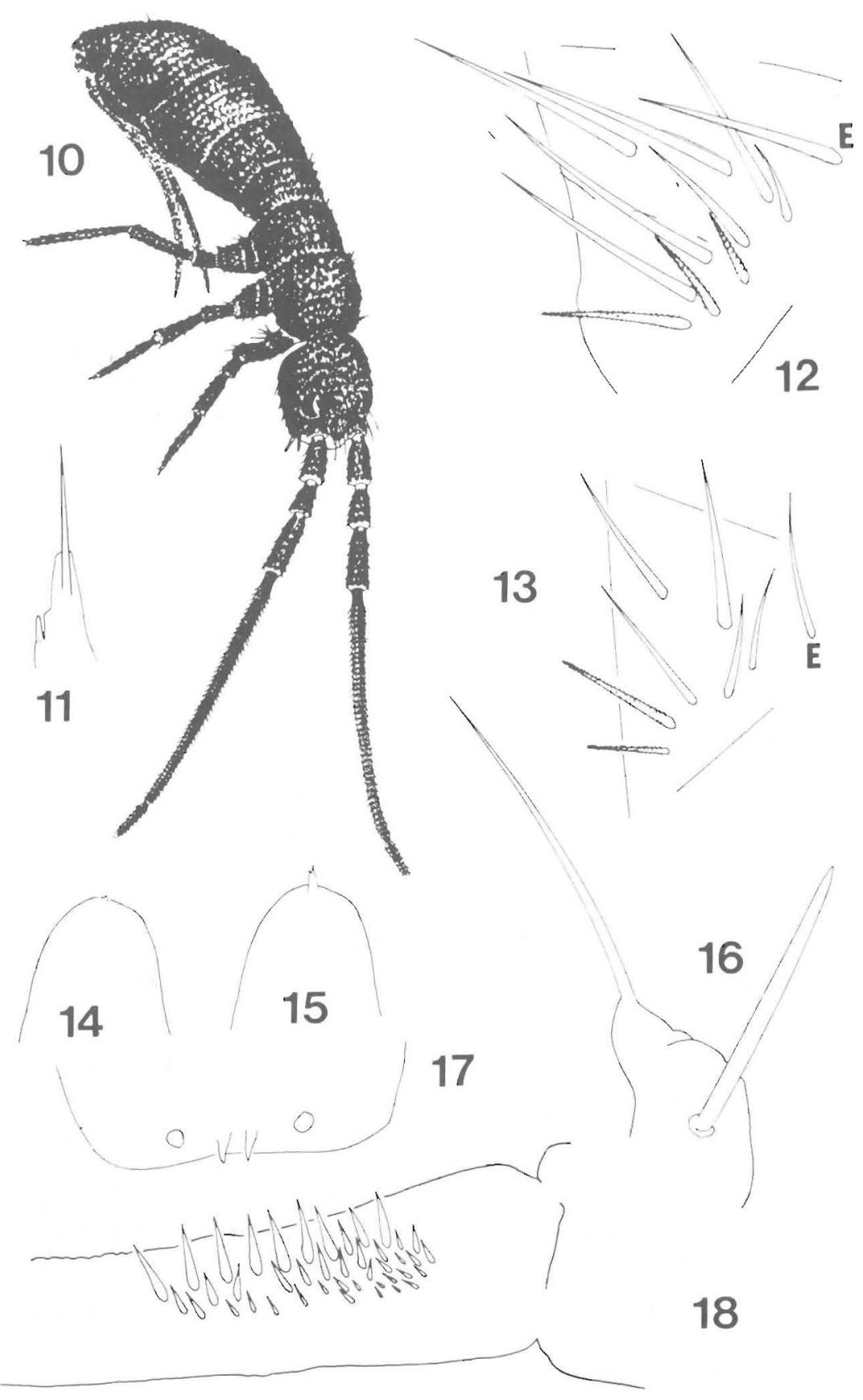

Plate II. Dicranocentrus marias.

10. Habitus. 11. Outer labial papilla with its differentiated seta. 12. Chaetotaxy of labial triangle, large specimen. 13. As preceding, small specimen. 14. Apex of Ant. 6. 15. As preceding, but with larger pin seta. 16. Maxillary palp. 17. Labral papillae (type III). 18. Dental spine arrangement. 
chaetotaxy seen only in one immature where seta $\mathrm{E}$ is smooth and posterior row consists of two ciliated setae. Setae of maxillary palp (fig. 70 ) as in circulatus. Setae of PLQ ciliated, other setae of venter of head also ciliated. Furcula without smooth setae.

Dicranocentrus marias Wray 1953 (12): 140.

Dicranocentrus silvestrii Absolon 1901 (1) sensu Denis (3): 147-149, Denis (4): 255-258.

Habitus as in figure 10. Color of live specimens with full coat of scales iridescent metallic black. Specimens with few scales cream-yellow to dark brown. Pin seta of Ant. 6 found in 2 out of more than 60 specimens studied; in one individual pin seta very small (fig. 14), barely visible at $1,500 \times$ (oil immersion, phase contrast); in another well developed (fig. 15). Labral papillae (fig. 17) of type III (outer pair rounded, flaplike; inner pair strongly conelike). Labial triangle as in figures 12,13 ; posterior row with smooth and ciliated setae. Labial chaetotaxy variable, number of setae increases with age. Subapical seta of maxillary palp clearly differing in shape from apical seta (fig. 16). Differentiated seta of outer labial papilla short, placed far back on its papilla (fig. 11). All setae of venter of head, including PLQ, smooth. Dental spine arrangement as in figure 18.

Dicranocentrus millsi Mari Mutt 1979 (9): 61.

Dicranocentrus millsi cubensis Mari Mutt 1979 (9): 62. NEW SYNONYMY

Habitus and distribution of pigment as in figures 20 and 69. Coloration variable between members of different populations but not so variable among sympatric individuals. Pin seta present (fig. 23). Labral papillae of type III (fig. 25). Labial triangle as in figure 21, posterior row with smooth setae and scales. Subapical seta of maxillary palp much longer than apical seta (fig. 24). Differentiated seta of outer labial papilla as in figure 22. All setae of venter of head (including PLQ) smooth. Structure of claws as in figure 19, some Cuban specimens with second distal unpaired tooth. Tenent hair apically lanceolate or clavate. Dorsum of manubrium and proximal dorsal portion of dentes with several rows of lightly ciliated setae but without smooth erect setae. Dental spine arrangement as in figure 26, outer margin of dentes without spines.

\section{Comments}

A study of type material at the Illinois Natural History Survey revealed that $D$. millsi, as originally described, is a composite species including $D$. biseriatus n. sp. described below. D. millsi, in the new sense, is known in Haiti only from the type locality.

A reexamination of Cuban specimens led to the discovery of some individuals with a few dental spines forming a second inner row. In view 


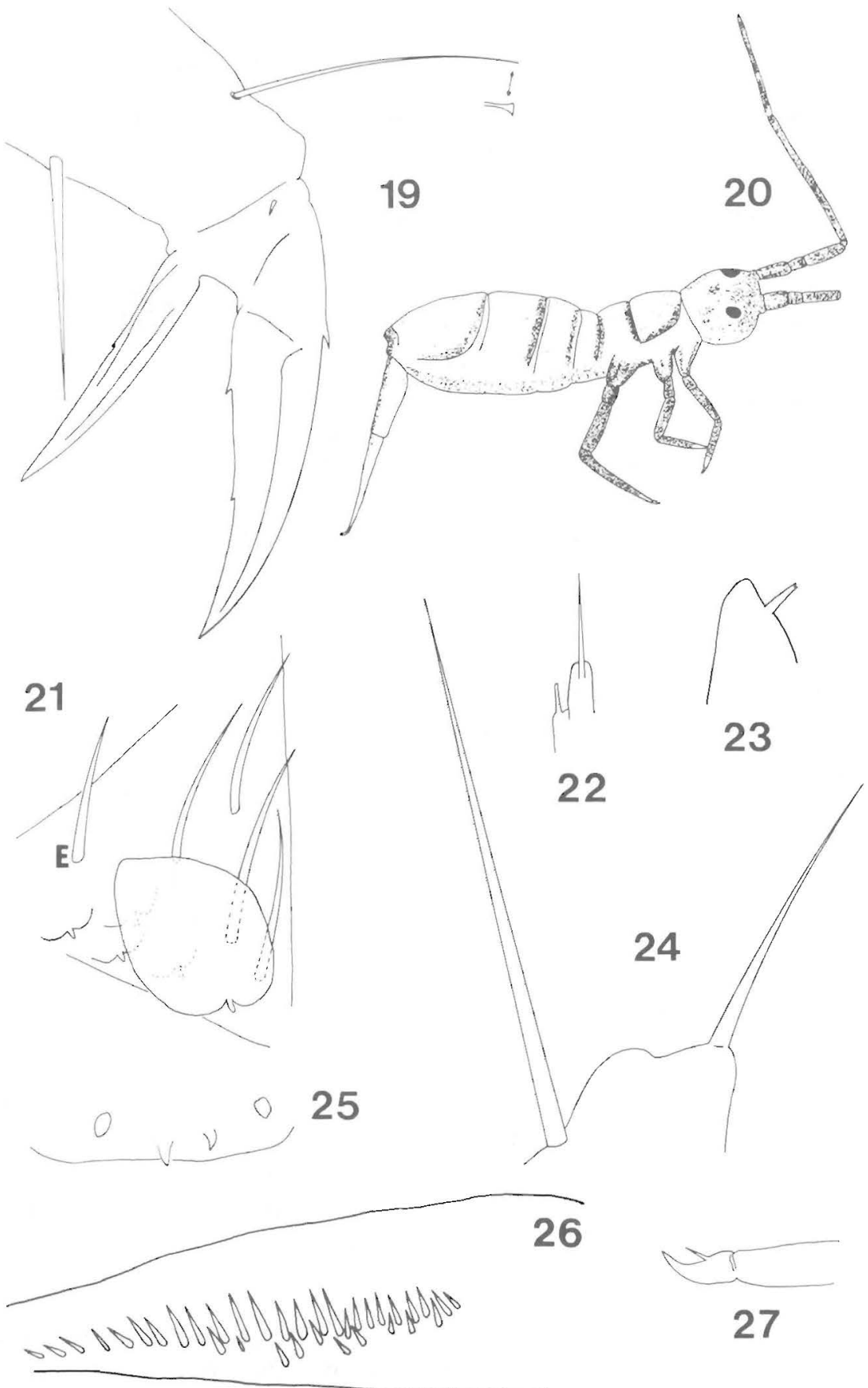

Plate III. Dicranocentrus millsi (except for figure 27).

19. Metathoracic claws. 20. Habitus and distribution of pigment (compare with figure 69). 21. Labial triangle, note presence of scales. 22. Outer labial papilla. 23. Apex of Ant. 6 with pin seta. 24. Maxillary palp. 25. Labral papillae (type III). 26. Dental spine arrangement. 27. D. antillensis-abnormal mucro. 
of the variation in color pattern exhibited by this species (see next paragraph) it seems preferable to regard $D$. millsi cubensis as a local form.

Two collections from the Dominican Republic (see material examined) produced specimens with a striking banded pattern (fig. 69). One of the collections consists of a single specimen, but the other sample includes this form and the typical one (fig. 20). Since color pattern is the only difference between both groups, the banded specimens are being called D. millsi. Specimens reported from the Dominican Republic by Mari Mutt (7) as Dicranocentrus sp. are millsi.

\section{Material examined}

(In addition to that listed by Mari Mutt (9): 62): Dominican Republic, Provincia La Vega, El Río Bonao, km. 24, 600-800 m., Feb. 7, 1975, ravine leaf litter, W. L. Brown, FM 75-281, 12 specimens. Provincia la Vega, Ciénaga, 1,100 m., soil and leaf litter, Feb. 4, 1975, W. L. Brown, 1 specimen (banded form).

The Field Museum of Natural History, Chicago, Illinois, has eight specimens from the first locality. The Illinois Natural History Survey and the author's collection have two specimens each from this locality. The specimen from the second locality is in the author's collection.

Dicranocentrus biseriatus NEW SPECIES Dicranocentrus millsi Mari Mutt 1979 (9): 61. Synonym in part.

This species is similar to the preceding in all respects except that individuals of the new species possess $2-7$ spines on the outer margin of the dentes (fig. 73), always have a second distal unpaired tooth on the inner margin of ungues, and tenent hairs are always apically clavate (fig. 71). D. millsi lacks spines on the outer margin of the dentes and a second distal tooth on the ungues has been found only in specimens from Cuba. Dorsal head and body macrochaetotaxy are identical in both species. Figure 68 presents the habitus and pigment distribution of biseriatus (compare with figure 20).

Dicranocentrus biseriatus is also very close to D. spinosus Prabhoo 1971 (10), a species from southern India. Both taxa may be separated by the arrangement of $\mathrm{A}$ setae on the head, some aspects of the chaetotaxy of Ths. 2-3 and Abd. 4, relative lengths of Ants. 5-6, and the presence of lanceolate tenent hairs in spinosus (clavate in biseriatus).

\section{Material examined}

Haiti, 3 km. above SHADA headquarters, 2,200 m., May 28, 1950, rotting pine wood, H. B. Mills, holotype and seven paratypes, all at the Illinois Natural History Survey. All Haitian localities listed by Mari Mutt 

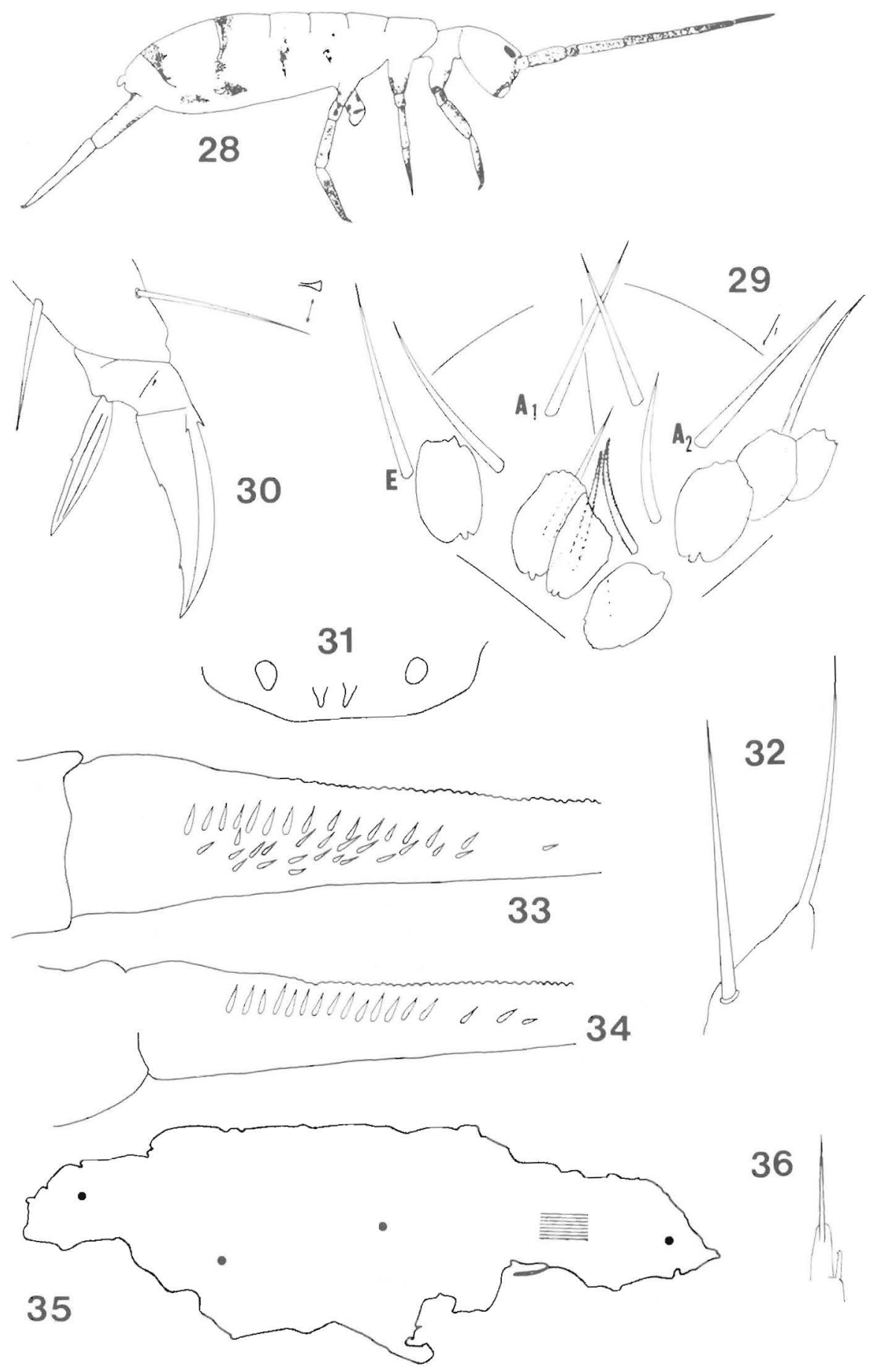
(9): 62 under D. millsi belong to biseriatus with the exception of the type locality of millsi.

Dicranocentrus antillensis Mari Mutt 1979 (9): 57.

Habitus and pigmentation as in figure 28. Pin seta absent. Labral papillae (fig. 31) of type III, lateral pair developed into rounded tubercles. Labial chaetotaxy as in figure 29 , second row with smooth setae, ciliated setae, and scales. Setae of maxillary palp as in figure 32. Differentiated seta of outer labial papilla as in figure 36. Setae of PLQ and all others of venter of head smooth. Structure of claws as in figure 30. Tenent hairs apically lanceolate or clavate, both types not found in same specimen. Dorsum of manubrium with double row of many very lightly ciliated setae but without smooth erect setae. Dental spine arrangement as in figures 33 or 34 , intermediate arrangements unknown. One abnormal mucro as in figure 27.

Dicranocentrus antillensis antillensis nominate subspecies

This subspecies is characterized by its clavate tenent hairs (fig. 30) and a single row of dental spines (fig. 34). It occurs in the southern Haitian peninsula and Jamaica (fig. 35).

\section{Dicranocentrus antillensis jamaicensis NEW SUBSPECIES}

This subspecies is characterized by its lanceolate tenent hairs (fig. 30) and three rows of dental spines (fig. 33). It occurs only in Jamaica (fig. 35 ), and has not been found sympatrically with the nominate subspecies.

Comments: One locality (see legend to figure 35) produced an individual with clavate tenent hairs and three rows of dental spines. The other specimens from this locality were of the new subspecies.

Dicranocentrus colombiensis Mari Mutt 1979 (9): 23.

Habitus and distribution of pigment as in figure 72. Pin seta present (fig. 44). Labral papillae of type III (fig. 39). Chaetotaxy of labial triangle as in figure 38 , note presence of smooth setae, ciliated setae, and scales. Setae of maxillary palp as in figure 42. Differentiated seta of outer labial papilla thicker and longer than in most species (figs. 40, 41). Setae of PLQ and all others of venter of head smooth. Claw structure as in figure

Plate IV. Dicranocentrus antillensis.

28. Habitus and distribution of pigment. 29. Labial triangles. 30. Metathoracic claws, 31. Labral papillae (type III). 32. Maxillary palp. 33. Dental spine arrangement- $D$. antillensis jamaicensis. 34. As preceding but nominal subspecies. 35. Distribution of the two subspecies-dots indicate distribution of nominal subspecies. From left to right: Hanover, Dolphin Head; St. Elizabeth, below Maggoty Falls; Clarendon, Bull Head Mt., St. Thomas, Corn Pass Gap. Shaded area indicates distribution of antillensis jamaicensis and includes four localities: St. Andrew, Ridge of John Crow Peak; St. Thomas, Fairy Glade; St. Thomas, west side of John Crow Mountains; Portland, Portland Gap. A specimen with characteristics of both subspecies was found in the latter locality (see text). 36. Outer labial papilla. 

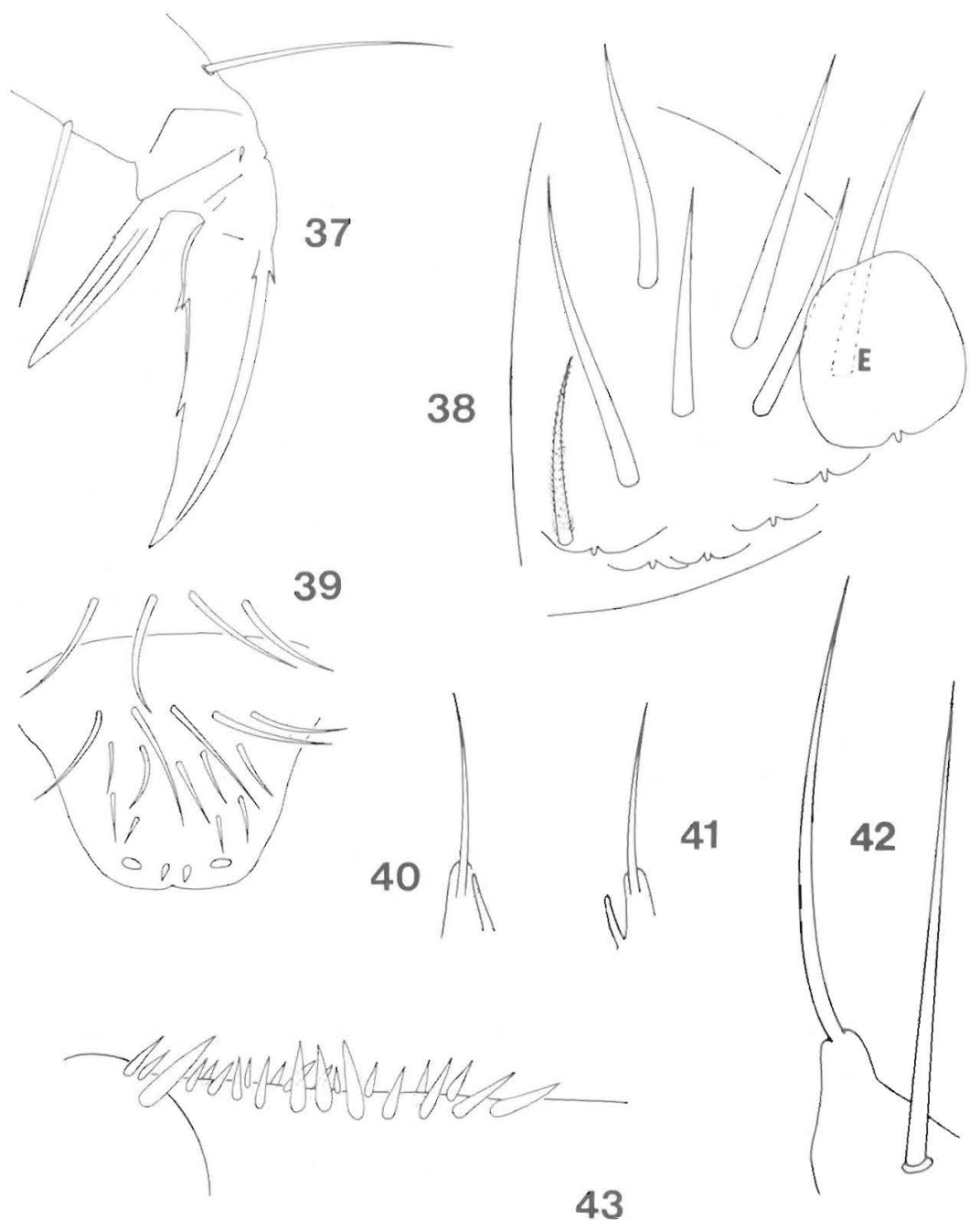

43
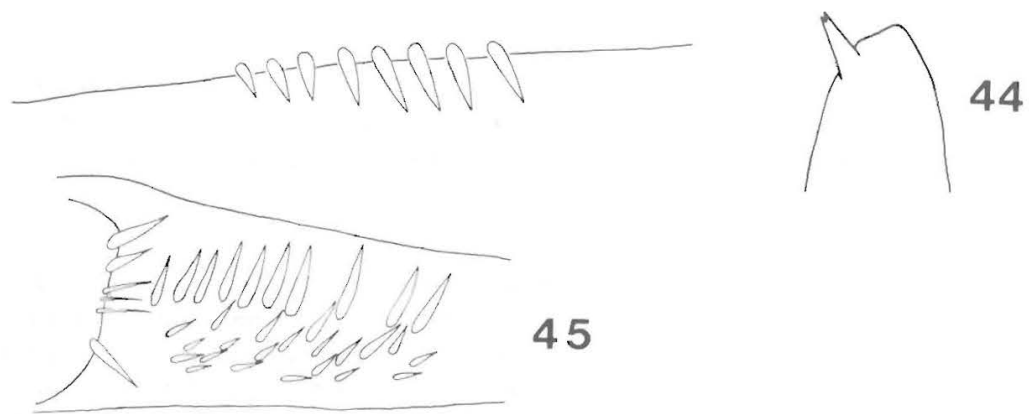

Plate V. Dicranocentrus colombiensis.

37. Metathoracic claws. 38. Labial triangle. 39. Labrum and labral papillae (type III). 4041. Outer labial papilla. 42. Maxillary palp. 43. Dental spine arrangement, dorsal view. 44. Apex of Ant. 6 with pin seta. 45. Dental spine arrangement, lateral view. 

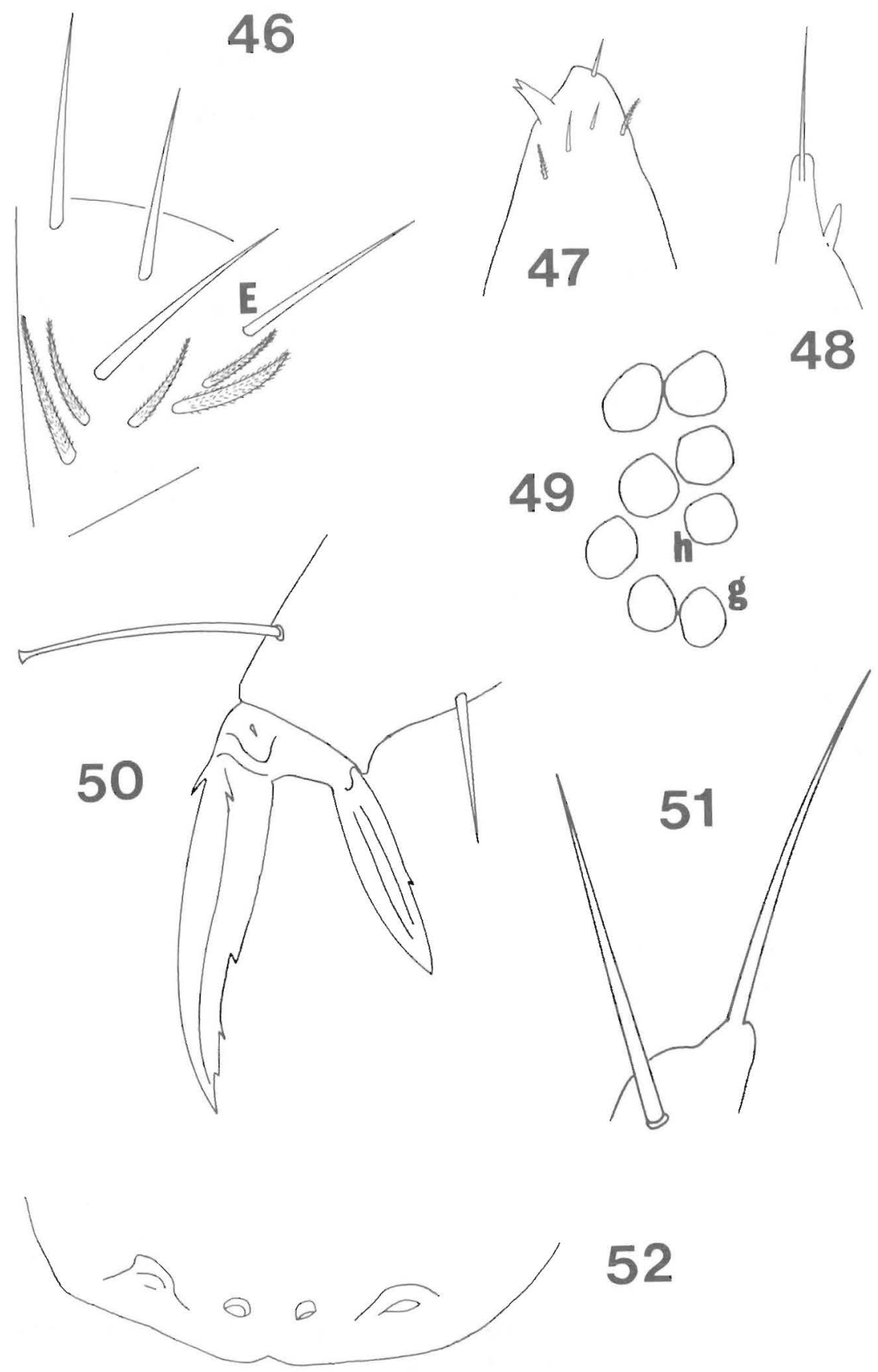

Plate VI. Dicranocentrus nigritus.

46. Labial triangle. 47. Apex of Ant. 6 with pin seta. 48. Outer labial papilla. 49. Left eye patch, note slight reduction of eyes g\&h (compare with figure 55). 50. Metathoracic claws. 51. Maxillary palp. 52. Labral papillae (type intermediate between II \& III). 
37. Furcula without smooth setae. Dental spine arrangement as in figures 43 and 45 ; note presence of simple spines on dental lobe.

\section{Dicranocentrus nigritus Mari Mutt 1979 (9): 23.}

Pin seta present (fig. 47). Eyes g\&h not markedly reduced in diameter (fig. 49). Labral papillae of type III (fig. 52), lateral pair developed into rounded tubercles which in profile appear somewhat conelike. Labial chaetotaxy as in figure 46 , posterior row with smooth and ciliated setae. Setae of maxillary palp (fig. 51) similar in length and shape. Differentiated seta of outer labial papilla as in figure 48. Setae of PLQ smooth but a ciliated seta may be found between them; other setae of venter of head smooth or ciliated in about equal numbers. Structure of claws as in figure 50 , tenent hair apically clavate. Furcula without smooth setae.

\section{Dicranocentrus schoetti Mari Mutt 1979 (9): 56.}

Habitus typical of genus. Eyes g\&h reduced in diameter, as usual for genus (fig. 55). Pin seta (fig. 53) observed in a regenerated Ant. 5. Labral papillae (fig. 58) of type III, outer pair developed into rounded tubercles. Labial chaetotaxy as in figure 54, posterior row with smooth, ciliated setae, and scales. Subapical seta of maxillary palp longer than apical seta (fig. 56). Differentiated seta of outer labial papilla as in figure 57 (this figure also shows some of the adjacent setae). Setae of PLQ smooth, others of venter of head smooth or ciliated. No smooth setae seen on furcula but most setae have been lost. Dental spine arrangement as in figure 59.

\section{Dicranocentrus platensis (Izarra)}

Alloscopus platensis Izarra 1972 (5): 537.

Dicranocentrus platensis (Izarra). Mari Mutt (8): 248. Mari Mutt (9): 71. Dicranocentrus silvestrii Absolon 1903 (1) sensu Bonet (2): 182.

Habitus typical of genus. Length up to $3.4 \mathrm{~mm}$. Ants. $5 \& 6$ deeply pigmented throughout. Apical third of Ant. 4 colored. Ant. 2 with scarce pigment. Mouth cone and antennae surrounded by pigment. Coxae of all legs with some color. Trochanters of prothoracic legs unpigmented, of mesothoracic legs with little pigment, of methathoracic legs more thoroughly pigmented. Distal $3 / 4$ of tibiotarsi deeply pigmented, rest of animal unpigmented.

Ant. 5 about twice as long as Ant. 6 (fig. 62), both segments conspicuously annulated. Apex of Ant. 6 with bifurcated pin seta. Eyes g\&h reduced in diameter (see Bonet (2): 183, fig. XVIII). Labral papillae (fig. 67) of type II, inner pair conspicuously conelike, outer pair more rounded. Labial chaetotaxy as in figure 61, posterior row with smooth, ciliated 


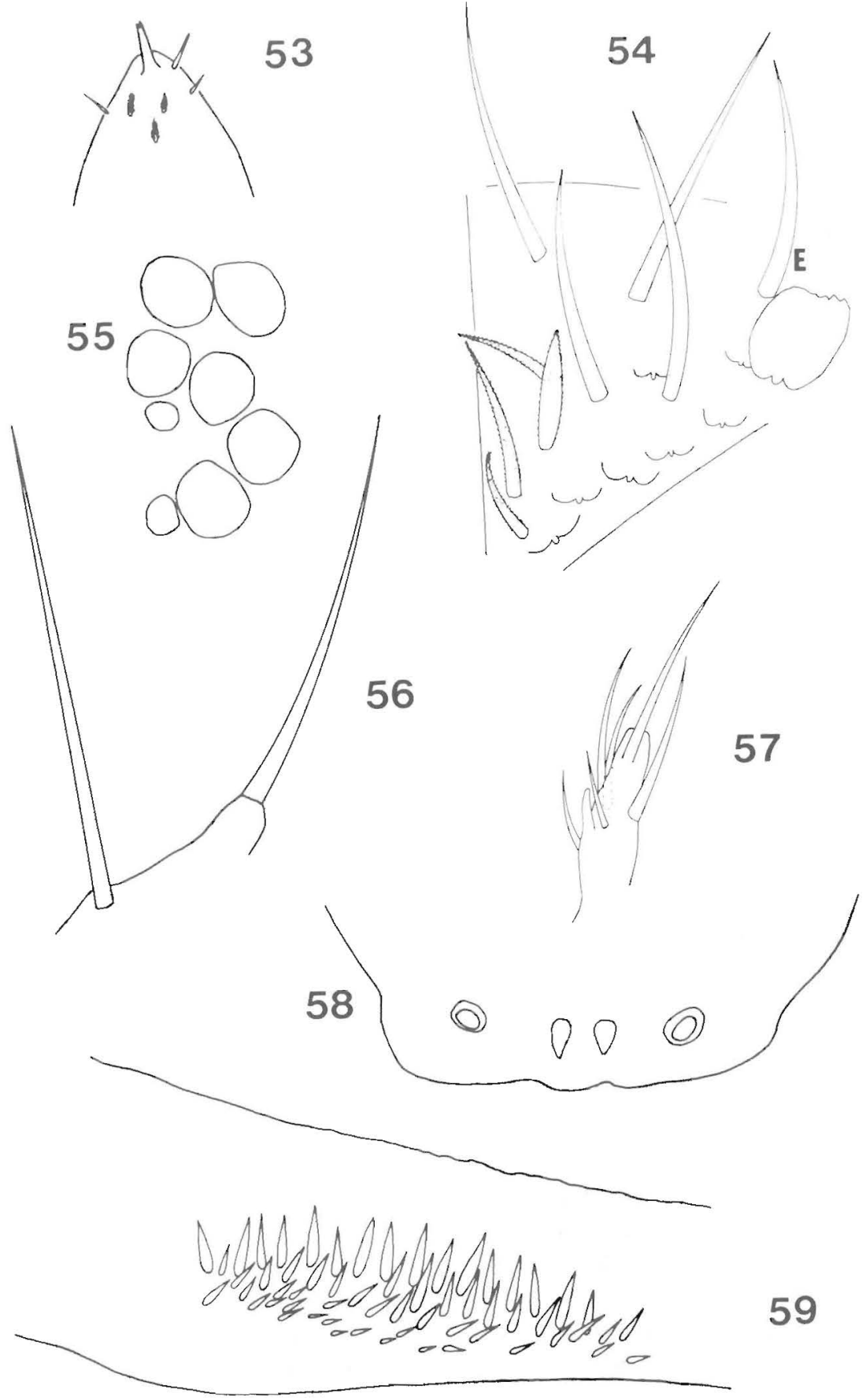

Plate VII. Dicranocentrus schoetti.

53. Apex of Ant. 6 with pin seta. 54. Labial triangle, note many scales. 55. Right eye patch. 56. Maxillary palp. 57. Outer labial papilla with its differentiated seta. 58. Labral papillae (type III). 59. Dental spine arrangement, right end of figure leads to mucro. 
setae, and scales. Setae of maxillary palp as in figure 63. Differentiated seta of outer labial papilla as in figure 66. Setae of PLQ smooth, others on venter of head smooth or ciliated. Dorsal head macrochaetotaxy as in figure 60 .

Tibiotarsi without smooth setae. Unguis (fig. 64) with inner basal pair of teeth and 2 distal unpaired teeth. Unguiculus with small tooth halfway along outer lamella. Tenent hair lanceolate or slightly clavate. Dorsal body macrochaetotaxy as in figure 65. Furcula without smooth setae. Dorsum of manubrium with few scales. Dentes with about 60 spines arranged in 4-5 longitudinal rows (see Bonet (2): 183, fig. XVIII; Izarra (5): 538, fig. 6).

\section{Diagnosis}

This species is very similar to $D$. longicornis (Carpenter) from the Seychelles Islands but differs by the chaetotaxy of Th. 3 (8 setae in longicornis, 9 in platensis) and by the structure of the claws (ungues tridentate in longicornis, quadridentate in platensis; tooth on unguiculus placed proximally in Carpenter's species, placed upon middle of lamella in Izarra's species).

\section{Comments}

Study of a syntype, other specimens from Buenos Aires Province, and the description by Bonet (2) of $D$. silvestrii has led me to conclude that platensis and silvestrii sensu Bonet (2) are cospecific.

Of all the South American species, platensis is most similar to silvestrii in its original sense. See Mari Mutt (9): 72-73 for a discussion of the status of this name.

\section{Material examined}

Argentina, Buenos Aires Province, La Plata, leaf litter from the forest in front of the Natural History Museum, Sept. 24, 1970, J. Najt, 1 syntype (slide no. 3460). Buenos Aires Province, Punta Lara marginal forest, 14 km. from La Plata, Feb. 25, 1976, J. Najt, 7 specimens. Punta Lara marginal forest, Sept. 1977, J. Najt, 3 specimens. Buenos Aires, Zelaya, April 9, 1937, B. Daguerre, 4 specimens. Tucumán Province, Jardín del Lillo (Universidad), May 1975, J. Najt, 1 specimen.

The syntype is deposited at La Plata Museum, Universidad de La Plata, Facultad de Ciencias Naturales y Museo, División de Entomología. The other specimens are in the author's collection. 


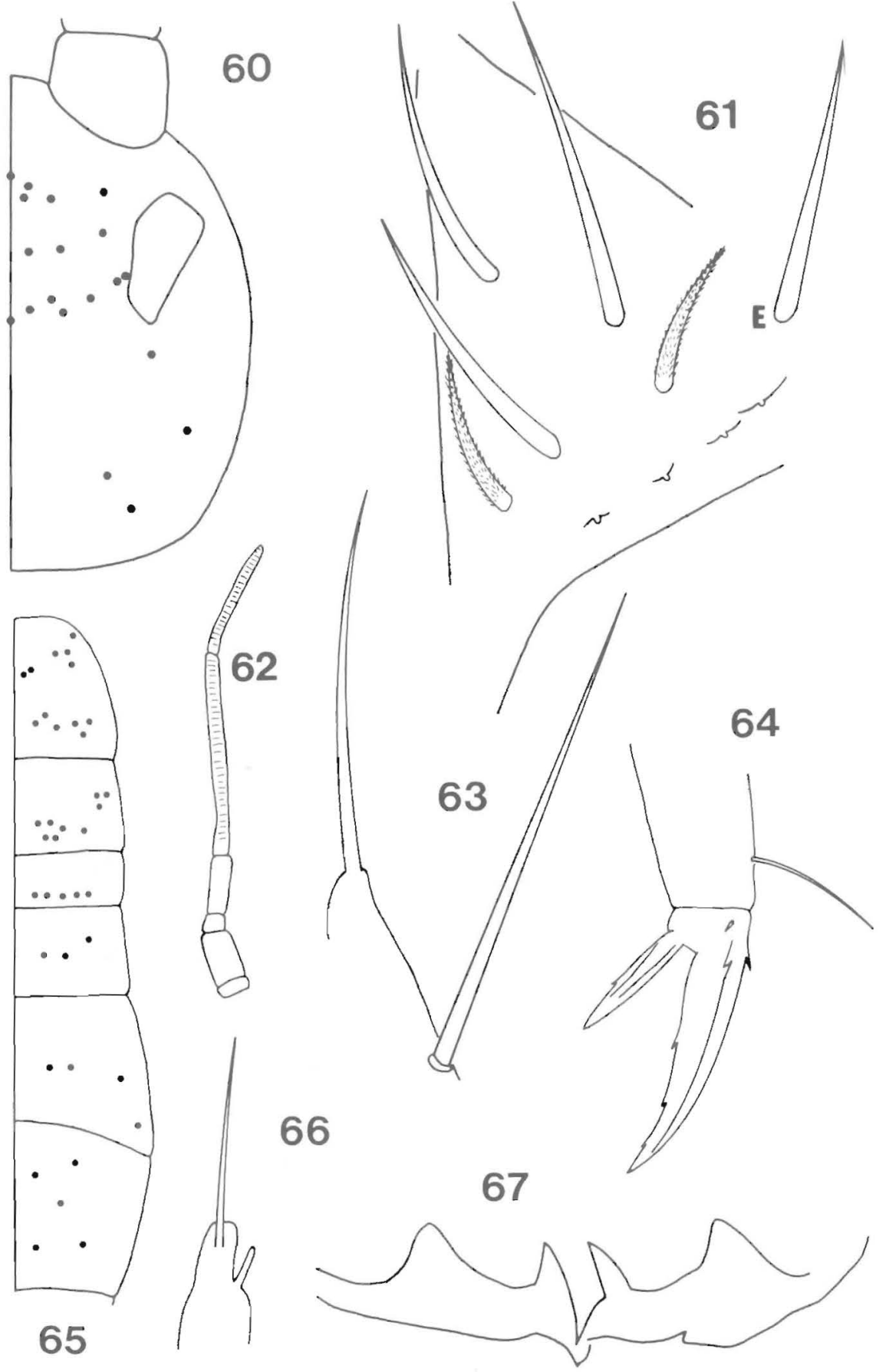

Plate VIII. Dicranocentrus platensis.

60. Dorsal head macrochaetotaxy. 61. Labial triangle, note scales. 62. Antenna. 63. Maxillary palp. 64. Claws. 65. Dorsal body macrochaetotaxy. 66. Outer labial papilla. 67. Labral papillae (type II). 

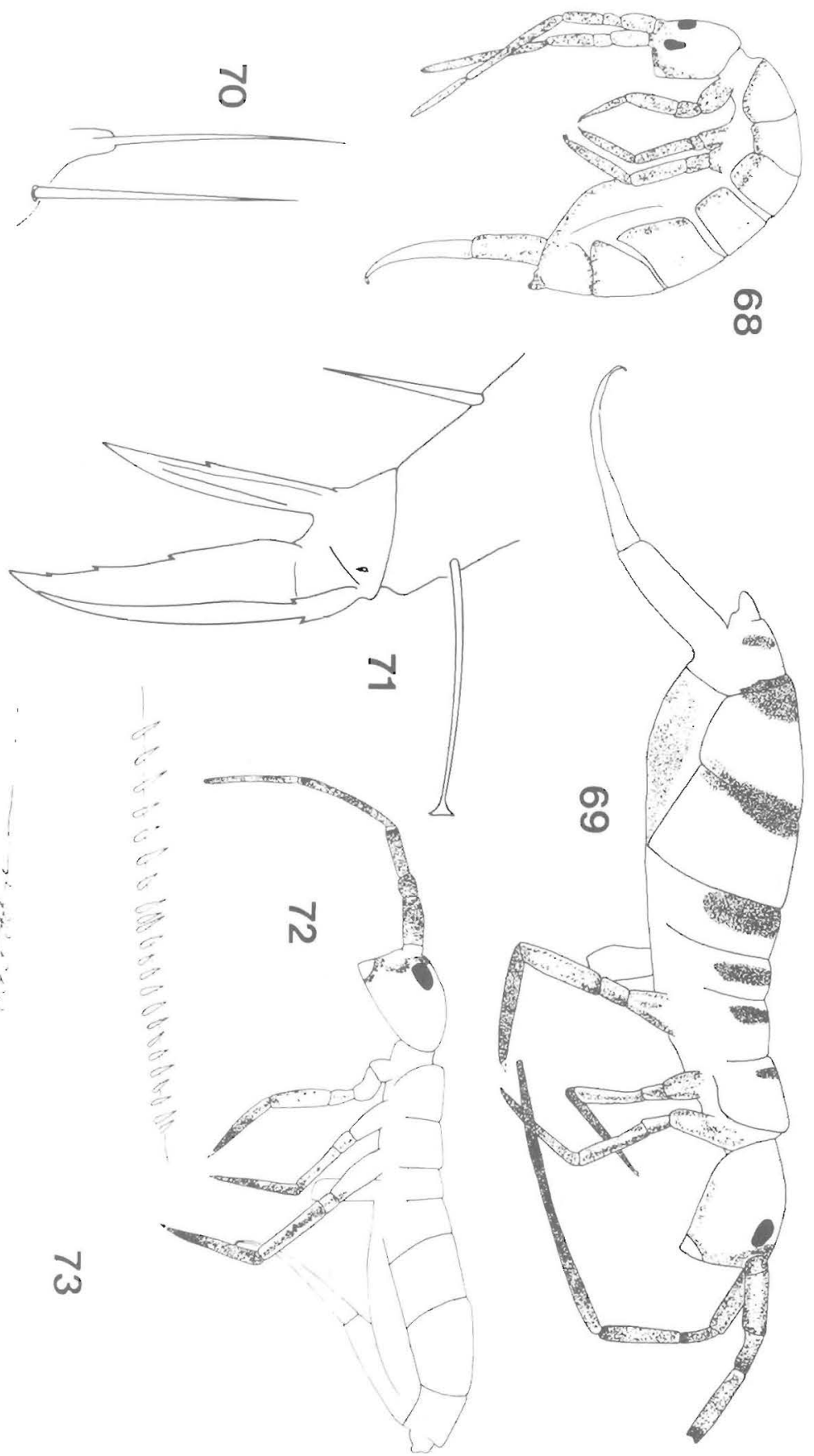

Plate IX.

68. D. biseriatus-habitus and distribution of pigment. 69. D. millsi-habitus and distribution of pigment of a specimen from the Dominican Republic (compare with figure 20). 70. P. christianseni-maxillary palp. 71. D. biseriatus-metathoracic claws. $72 . D$. colombiensis-habitus and distribution of pigment. 73. D. biseriatus-dental spine arrangement. 


\section{RESUMEN}

Se propone el nuevo género Pseudodicranocentrus para dos especies, circulatus y christianseni, previamente descritas y colocadas por el autor en Dicranocentrus. El nuevo género es muy similar a este último, pero se distingue por !a presencia de sedas cefálicas $A_{1}, P s$, sedas prelabrales bifurcadas y espinas compuestas dispuestas circularmente y colocadas sobre el lóbulo dental. Se describen además $D$. biseriatus $n$. sp. de Haití y $D$. antillensis jamaicensis $\mathrm{n}$. ssp. de Jamaica. Se sinonimiza $D$. millsi cubensis Mari Mutt 1979 con la forma nominal. Se añaden detalles a las descripciones de los siguientes Dicranocentrus neotropicales: antillensis, colombiensis, marias, nigritus, platensis, y schoetti.

\section{LITERATURE CITED}

1. Absolon, K., 1903. Untersuchungen über Apterygoten auf der Sammlungen des Weiner Hofmuseums, Ann. des k. k. Naturhis. Hofmus. Wien, 18: 91-111 \& 2 plates.

2. Bonet, F., 1934. Colémbolos de la República Argentina, Eos, Madrid, 9: 123-194.

3. Denis, J. R., 1931. Contributo alla conoscenza del "microgenton" di Costa Rica. II, Collemboles de Costa Rica avec une contribution aux espèces de l'ordre, Boll. Regio Lab. Entomol. Agrar. Portici, Italy, 25: 69-170.

4. Denis, J. R., 1933. Contributo alla conoscenza del "microgenton" di Costa Riea. III, Collemboles de Costa Rica avec une contribution aux espèces de l'ordre, Boll. Regio Lab. Entomol. Agrar. Portici, Italy, 27: 222-322.

5. Izarra, D. C. de, 1972. Alloscopus platensis, una nueva especie de La Plata, Provincia de Buenos Aires, 31(83): 537-39.

6. Mari Mutt, J. A., 1978a. A revision of the scaled Orchesellinae (Insecta: Collembola: Entomobryidae), Ph.D. thesis, unpublished, University of Illinois at Urbana-Champaign, $292 \mathrm{pp}$.

7. $-1978 b$. Fifteen new records and a new species of Collembola (Insecta) from the Dominican Republic, Fla. Entomol., 60(4): 28I-285.

8. - 1978c. The taxonomic status of Alloscopus and redescriptions of its two species (Collembola: Entomobryidae), Pan-Pac. Entomol., 53(4): 241-249.

9. - 1979. A revision of the genus Dicranocentrus Schött (Insecta: Collembola: Entomobryidae), Univ. P.R. Agri. Exp. Sta. Bull., 259, 79 pp.

10. Prabhoo, N. R., 1971. Soil and leaf litter Collembola of South India. I. Arthropleona, Orient. Ins., 15: 1-46.

11. Schott, H. G., 1893. Beiträge zur kenntnis der insektenfauna von Kamerun, Bihang. till K. Sven. Vetenskapsakad. Handl., 19: 5-28.

12. Wray, D. L., 1953. New Collembola from Puerto Rico, J. Agri. Univ. P.R., 37 (2):140 150. 